Іван Юрійович Марко (доктор екон. наук, професор) ${ }^{l}$

Ірина Матвіївна Чернишова (канд. військ. наук, с.н.с.) ${ }^{1}$

Тарас Володимирович Череватий ${ }^{2}$

${ }^{1}$ Центральний науково-дослідний інститут Збройних Сил Украӥни, Київ, Украӥна

${ }^{2}$ Головне квартирно-експлуатаційне управління Збройних Сил Украӥни, Київ, Украӥна

\title{
МЕТОДИКА РОЗПОДІЛУ ФІНАНСОВИХ РЕСУРСІВ МІЖ ЗАХОДАМИ РОЗКВАРТИРУВАННЯ З'ЄДНАНЬ (ЧАСТИН) У ПОЛЬОВИХ УМОВАХ
}

У статті представлена удосконалена методика розподілу виділених фінансових ресурсів між заходами, щуо виконуються під час розквартирування з'єднань (частин) Збройних Сил Украӥни в польових умовах з метою підтримання певного рівня боєздатності изих з'єднань (частин). Методика призначена для обгрунтування обсягу фінансових ресурсів необхідних для проведення успішного розквартирування з'єднання (частини) у польових умовах, а також для визначення порядку розподілу виділених фінансових ресурсів між заходами з розквартирування з'єднань (частин) у польових умовах. Застосовувати ії пропонується в итабах (службах) під час визначення потреби витратних матеріальних запасів, необхідних для здійснення зазначеного розквартирування, а також для оптимального розподілу виділених фінансових ресурсів між заходами з розквартирування. Запропонована методика має певні переваги: по-перше формалізує взаємозв'язок результатів розквартирування військ (сил) в польових умовах з досяжним рівнем боєздатності; по-друге містить в собі механізм розрахунку необхідних фінансових ресурсів для здійснення успішного розквартирування з'єднань (частин); по-третє, дозволяє оптимізувати розподіл виділених фінансових ресурсів між заходами розквартирування з'єднання (частини)з метою максимізації рівня його боєздатності. Застосування удосконаленої методики надасть можливість уникнути помилок під час визначення необхідних фінансових ресурсів для розквартирування військ (сил) в польових умовах, а також здійснити більш обтрунтований розподіл виділених фінансових ресурсів.

Ключові слова: розквартирування з'єднань (частин) в польових умовах; розподіл фінансових ресурсів; рівень боєздатності.

\section{Вступ}

Постановка проблеми. Сьогодні значна увага приділяється питанням підтримання бойової здатності Збройних Сил України (далі - ЗС України), а також витрачанню бюджетних коштів на їх забезпечення. Вимоги до досягнення ЗС потрібного рівня боєздатності змушують більш детально обгрунтовувати фінансові витрати на їх потреби, зокрема під час розквартирування військ (сил) у польових умовах. Отже, розгляд питань із обгрунтування розподілу фінансового ресурсу між заходами розквартирування 3'єднань (частин) у польових умовах у взаємозв'язку із рівнем їх боєздатності є актуальним завданням сьогодення.

Аналіз останніх досліджень і публікацій. Питання обгрунтування фінансових витрат на оборону розглядається в багатьох джерелах вітчизняних та зарубіжних науковців, зокрема в [1, 2]. Зазначене питання завжди було актуальним та в основному досліджувалося 3 точки зору взаємозв'язку між обсягом оборонних видатків та розвитком економіки держави в цілому. В умовах обмеженості ресурсів необхідно здійснювати розподіл виділених фінансових ресурсів на ті чи інші заходи 3 метою максимізації впливу цих заходів на боєздатність з'єднань (частин). До того ж, питання визначення необхідного фінансового ресурсу, зокрема для розквартирування з'єднань (частин) у польових умовах та розподілу цих ресурсів між заходами із розквартирування військ потребують удосконалення та більш детального дослідження.

Враховуючи це мета статті полягає у представленні удосконаленої методики розподілу виділених фінансових ресурсів на заходи розквартирування з'єднань (частин) у польових умовах 3 метою максимізації ймовірності їх успішного виконання.

\section{Виклад основного матеріалу дослідження}

Методика розподілу фінансових ресурсів між заходами з розквартирування з'єднань (частин) у польових умовах (далі - Методика) призначена для обгрунтування обсягу фінансових ресурсів необхідних для проведення успішного розквартирування з'єднання (частини) у польових умовах, а також для визначення порядку розподілу виділених фінансових ресурсів між заходами 3 розквартирування з'єднань (частин) у польових умовах.

Застосовувати Методику пропонується в штабах (службах) під час визначення потреби витратних матеріальних запасів, необхідних для здійснення розквартирування з'єднань (частин) в 
польових умовах, а також для оптимального розподілу виділених фінансових ресурсів для розквартирування з'єднань (частин) в польових умовах між заходами з розквартирування.

Методика надасть можливість встановити взаємозв'язок між потрібним рівнем боєздатності з'єднання (частини) та обсягом фінансових ресурсів, які необхідно виділити для забезпечення цього рівня. Крім того, Методика дозволить здійснити розподіл зазначених ресурсів між заходами 3 розквартирування з'єднань (частин) у польових умовах.

Передумовами застосування Методики доцільно вважати таке.

1. Розквартирування військ у польових умовах - це розміщення з'єднань (частин, підрозділів), установ, військово-навчальних закладів у відведених, але не обладнаних для них місцях (таборах), а також створення необхідних умов для ix повсякденної діяльності та підтримання постійної бойової готовності.

2. Основними заходами розквартирування військ у польових умовах $\epsilon$ розгортання та обладнання: наметового містечка або містечка 3 використанням збірно-розбірних житлових конструкцій; пунктів господарського забезпечення; учбових місць; медичного пункту; санітарних пунктів; місць стоянки техніки; місць обслуговування та ремонту техніки.

Із цих заходів, на погляд автора, пріоритетними 3 точки зору важливості (впливу на боєздатність) та таких, що потребують більших затрат щодо з'єднання (частини), є заходи, пов'язані зі створенням:

наметового містечка або містечка 3 використанням збірно-розбірних житлових конструкцій (захід № 1);

пунктів господарського, зокрема продовольчого, забезпечення (захід № 2);

учбових місць (захід № 3).

3. Очевидно, що заходи 3 розквартирування з'єднання (частини), поряд із заходами інших видів забезпечення, певною мірою будуть впливати на досяжний рівень $\theta$ боєздатності цих військових формувань. Якщо прийняти виконаними заходи, які безпосередньо обумовлюють боєздатність (підготовка особового складу та забезпеченість матеріально-технічними засобами) з'єднання (частини), тоді можна вважати залежність рівня боєздатності з'єднання (частини) лише від результатів заходів 3 їх розквартирування.

Методика реалізується в п'ять етапів. Схема Методики розподілу фінансових ресурсів між заходами 3 розквартирування 3'єднань (частин) у польових умовах представлено на рис. 1 .

На першому етапі визначаються заходи 3 розквартирування з'єднання (частини) у польових умовах та вихідні дані для реалізації зазначених заходів. Тобто, визначається склад з'єднання (частини), що розквартировується; N, (люд.) чисельність особового складу; озброєння та військова техніка, яку необхідно розміщувати; місце розташування; пора року. За кожним і-м заходом встановлюються норми забезпечення $\alpha$ oi, які можуть приймати значення в межах від $\alpha$ minoi (мінімальне значення) до $\alpha$ maxoi (максимальне значення). Встановлюється площина $\mathrm{S}$ намету або збірно-розбірної житлової конструкції (м 2) та його вартість с1 (грн.), а також об'єм V польової кухні (л, дм 3) та іï вартість с2 (грн.). Крім того, визначається вартість с3 (грн.) місць для навчання, яка враховує вартість навчально-матеріальної бази.

На другому етапі, враховуючи попередньо визначені нормативи, розраховуються нормативні (плановані) значення показників розквартирування. Так для заходу №1 розгортання та обладнання наметового містечка обчислюється: по-перше, розрахункова кількість М01 наметів або збірно-розбірних житлових конструкцій (од.) за формулою

$$
\text { Mo1 }=\frac{\alpha_{\mathrm{ol}} \cdot \mathrm{N}}{\mathrm{S}} \text {; }
$$

по-друге, розрахункова вартість Co1 усіх потрібних наметів (розрахункова кількість) або збірно-розбірних житлових конструкцій (грн.) за формулою

$$
\mathrm{Col}=\mathrm{c} 1 \cdot \mathrm{Mo} 1 .
$$

Для заходу № 2 розгортання та обладнання пунктів харчового забезпечення обчислення відбуваються аналогічно. Розрахункова кількість M02 польових кухонь (од.) обчислюється формулою

$$
\mathrm{Mo} 2=\frac{\alpha_{\mathrm{o} 2} \cdot \mathrm{N}}{\mathrm{V}} .
$$

Розрахункова вартість Со2 усіх потрібних (розрахункова кількість) польових кухонь (грн.) обчислюється так

$$
\mathrm{Co} 2=\mathrm{c} 2 \cdot \mathrm{Mo} 2 .
$$

Для заходу № 3 розгортання та обладнання місць для навчань розрахункова кількість М03 місць для навчань (од.) обчислюється формулою

$$
\mathrm{Mo3}=\frac{\mathrm{N}}{\mathrm{L}} \text {, }
$$

де $\mathrm{L}$ - кількість військовослужбовців, що одночасно навчаються в одному учбовому місці (люд.).

Розрахункова вартість $\mathrm{Co3}$ усіх потрібних (розрахункова кількість) місць для навчань (грн.) обчислюється так

$$
\mathrm{Co} 3=\mathrm{c} 3 \cdot \mathrm{Mo} 3 .
$$

Результатом другого етапу $\epsilon$ визначення обсягу необхідних фінансових ресурсів Со для повного розквартирування певного з'єднання (частини) в польових умовах, що обчислюється за формулою

$$
\mathrm{C} 0=\mathrm{C} 01+\mathrm{C} 02+\mathrm{C} 03 .
$$




\section{Theoretical Foundations of Information Technologies Creation and Use}

\begin{tabular}{|c|c|c|c|c|c|c|c|}
\hline \multicolumn{8}{|c|}{ чення заходів розквартирування та вихідних да } \\
\hline \multicolumn{8}{|c|}{ 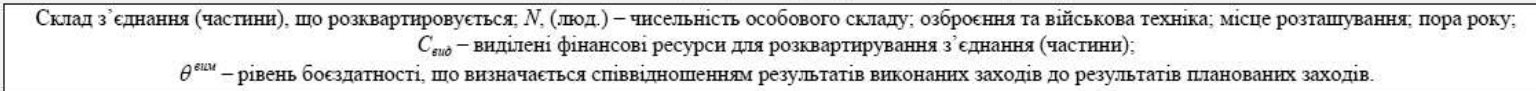 } \\
\hline \multicolumn{3}{|c|}{ Захід 1: Розгортання та обладнання наметового містечка } & \multicolumn{3}{|c|}{$\begin{array}{c}\text { Захід 2: Розгортання та обладнання пунктів харчового } \\
\text { забезпечення } \\
\end{array}$} & \multicolumn{2}{|c|}{$\begin{array}{c}\text { Захід 3: Розгортання та обладнання місць для } \\
\text { навчання }\end{array}$} \\
\hline $\begin{array}{c}\alpha_{01}^{\text {vin }} \leq \alpha_{01} \leq \alpha_{01}{ }^{\text {max }} \\
\text { норма забезпечення } \\
\text { площею } 1 \\
\text { військовослужбовця } \\
\text { (згілно з керівними } \\
\text { документами від } 2,5 \\
\text { до } 4 \mathrm{M}^{2} \text { ) }\end{array}$ & $\begin{array}{c}\text { площина } 1 \\
\text { намету або } \\
\text { 3бірно-розбірної } \\
\text { жнтлової } \\
\text { конструкціі } \\
\left(\mathrm{M}^{2}\right)\end{array}$ & $\begin{array}{c}C_{1} \\
\text { вартість 1 } \\
\text { намету або } \\
\text { збірно- } \\
\text { розбірної } \\
\text { житлової } \\
\text { конструкції } \\
\text { (грн) }\end{array}$ & \begin{tabular}{|c|}
$\alpha_{02}{ }^{\text {min }} \leq \alpha_{02} \leq \alpha_{02}{ }^{\text {*ax }}$ \\
норма забезпечення харчуванням \\
1 військовослужбовця на 1 добу \\
(згідно 3 керівними документамн \\
від 4 до 5 ккал (для розрахунку \\
об'єму польових кухонь \\
перераховується в л, дм ${ }^{3}$ ))
\end{tabular} & $\mid \begin{array}{c}V \\
\text { об'єм } 1 \\
\text { польовоі } \\
\text { кухні } \\
\left(\text { л, } \text { дм }^{3}\right)\end{array}$ & $\begin{array}{c}c_{2} \\
\text { вартість } 1 \\
\text { польової } \\
\text { кухні (грн) }\end{array}$ & \begin{tabular}{|c|}
$L$ \\
кількість військово- \\
службовців, що \\
одночасно \\
навчаються в 1 \\
учбовому місці \\
(люд.)
\end{tabular} & $\begin{array}{c}c_{3} \\
\text { вартість } 1 \text { учбового } \\
\text { місця, із } \\
\text { врахуванням } \\
\text { вартості навчально- } \\
\text { матеріальної бази } \\
\text { (грн) }\end{array}$ \\
\hline
\end{tabular}

\section{$\longrightarrow$}

\begin{tabular}{|c|c|c|c|c|c|}
\hline $\begin{array}{l}\text { Захід 1: Розгортання та об } \\
\text { Розрахункова кількість }\end{array}$ & $\begin{array}{c}\text { таднання наметового містечка } \\
\text { Розрахункова вартість усіх }\end{array}$ & \multicolumn{2}{|c|}{$\begin{array}{l}\text { Захід 2: Розгортання та обладнання пунктів } \\
\text { харчового забезпечення }\end{array}$} & \multicolumn{2}{|c|}{$\begin{array}{c}\text { 3ахід 3: Розгортання та обладнання місць } \\
\text { для навчання }\end{array}$} \\
\hline $\begin{array}{c}\mathrm{M}_{01} \text { наметів або збірно- } \\
\text { розбірних житлових } \\
\text { конструкцій (од.) }\end{array}$ & $\begin{array}{c}\text { потрібннх наметів або } \\
\text { збірно-розбірних житлових } \\
\text { конструкцій (грн) }\end{array}$ & \begin{tabular}{|c|} 
Розрахункова \\
кількість $\mathrm{M}_{02}$ \\
польових кухонь (од.)
\end{tabular} & \begin{tabular}{|c|} 
Розрахункова \\
вартість усіх \\
потрібних польових
\end{tabular} & \begin{tabular}{|c|} 
Розрахункова \\
кількість $\mathrm{M}_{03}$ \\
учбових місць (од.)
\end{tabular} & \begin{tabular}{|c|} 
Розрахункова \\
вартість усіх \\
потрібннх учбових
\end{tabular} \\
\hline $\mathrm{M}_{01}=\frac{\alpha_{\mathrm{ol}} \cdot \mathrm{N}}{\mathrm{S}}$ & $\mathrm{C}_{\mathrm{ol}}=\mathrm{c}_{1} \cdot \mathrm{M}_{\mathrm{ol}}$ & $\mathrm{M}_{02}=\frac{\alpha_{02} \cdot \mathrm{N}}{\mathrm{V}}$ & $\begin{array}{l}\text { кухонь (rpH) } \\
\mathrm{C}_{\mathrm{0} 2}=\mathrm{c}_{2} \cdot \mathrm{M}_{\mathrm{0} 2}\end{array}$ & $\mathrm{M}_{03}=\frac{\mathrm{N}}{\mathrm{L}}$ & $\begin{array}{l}\text { місць (грн) } \\
\mathrm{C}_{03}=\mathrm{c}_{3} \cdot \mathrm{M}_{03}\end{array}$ \\
\hline
\end{tabular}
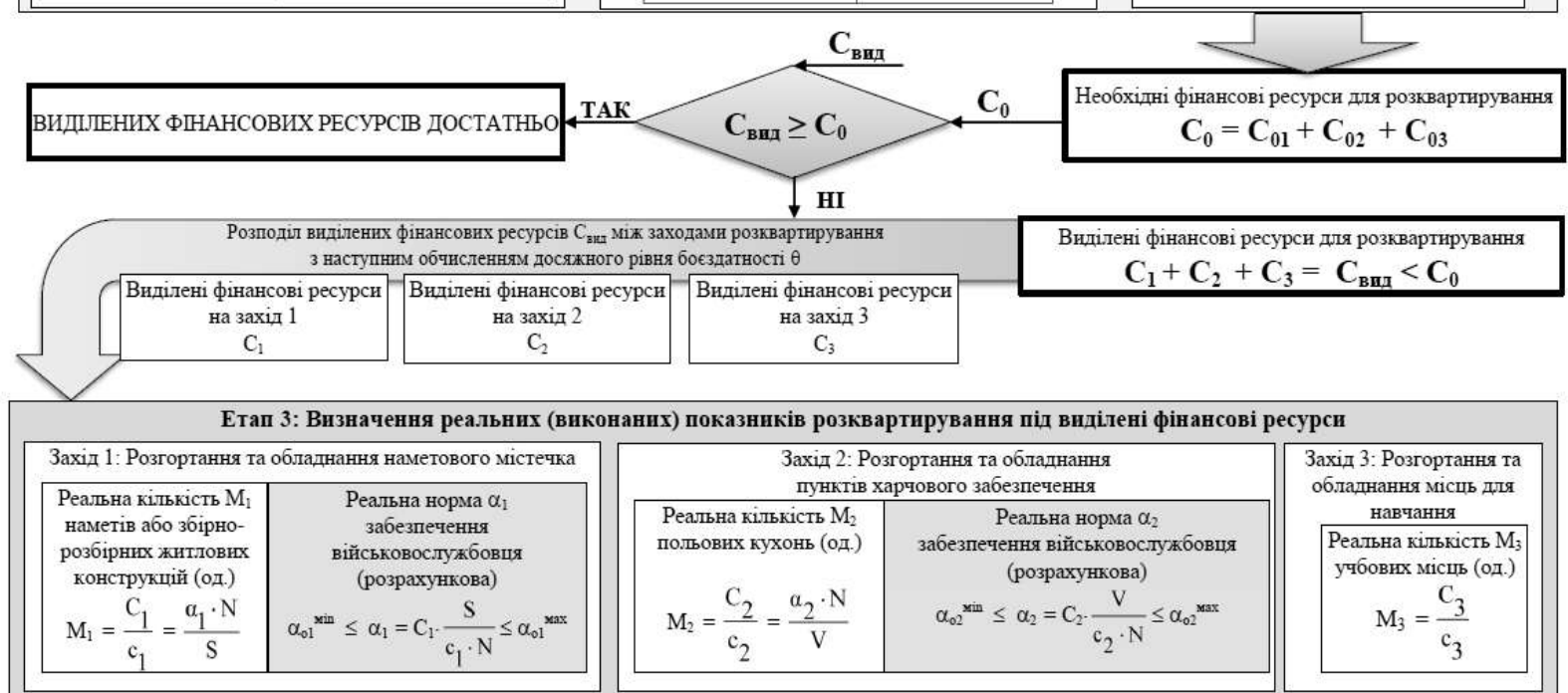

Виділені фінансові ресурси для розквартирування $\mathrm{C}_{1}+\mathrm{C}_{2}+\mathrm{C}_{3}=\mathrm{C}_{\text {вщд }}<\mathrm{C}_{0}$

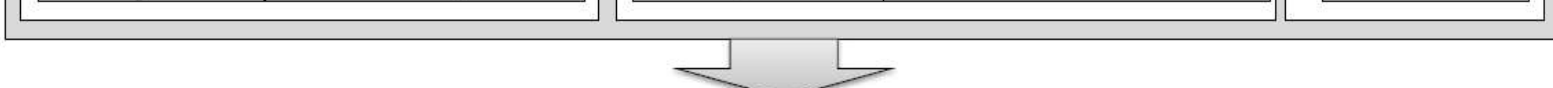

Етап 4: Оцінювання досяжного рівня боєздатності з'єднання (частини) залежно від показників розквартирування

Захід 1: Розгортання та обладнання наметового
містечка
досяжний рівень боєздатності $\theta_{1}$ за захід 1
$\theta_{1}=\frac{M_{1}}{M_{01}}=\frac{\alpha_{1}}{\alpha_{o 1}}=C_{1} \cdot \frac{\mathrm{s}}{\mathrm{c}_{1} \cdot \alpha_{\mathrm{ol}} \cdot \mathrm{N}}$

Захід 2: Розгортання та обладнання
пунктів харчового забезпечення
досяжний рівень боєздатності $\theta_{2}$ за захід 2
$\theta_{2}=\frac{\mathrm{M}_{2}}{\mathrm{M}_{\mathrm{o} 2}}=\frac{\alpha_{2}}{\alpha_{\mathrm{o} 2}}=\mathrm{C}_{2} \cdot \frac{\mathrm{V}}{\mathrm{c}_{2} \cdot \alpha_{\mathrm{o} 2} \cdot \mathrm{N}}$

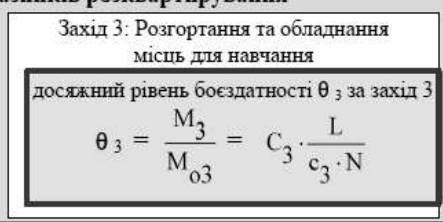

$$
\longrightarrow \text { W }
$$

Етап 5: Вирішення оптимізаційної задачі з досягнення максимального рівня боєздатності з'єднання (частини) в умовах внділених фінансових ресурсах $\mathrm{C}_{\text {вй }}$

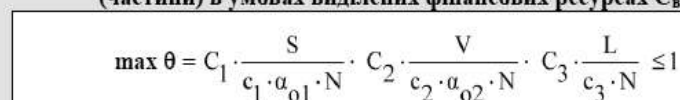

обмеження: $\mathrm{C}_{1}+\mathrm{C}_{2}+\mathrm{C}_{3}=\mathrm{C}_{\text {внд }}$

невідомі: $\mathrm{C}_{1}, \mathrm{C}_{2}, \mathrm{C}_{3}>0$

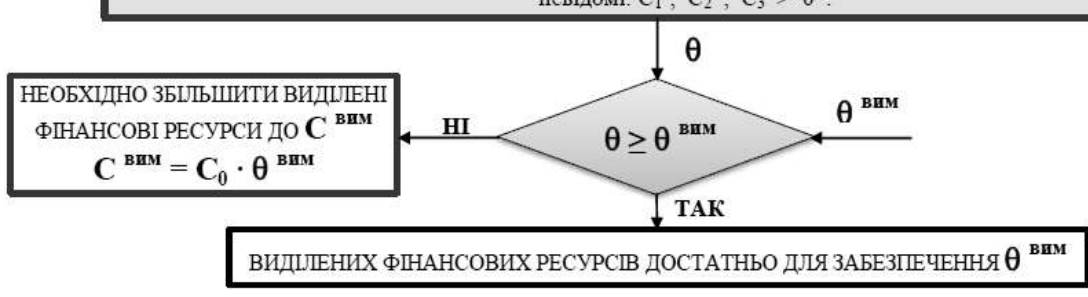

Рис. 1. Схема Методики розподілу фінансових ресурсів між заходами розквартирування з’єднань (частин) у польових умовах 
Якщо, фінансових ресурсів виділяється менше ніж необхідно Свид < 0 , то виділені ресурси слід перерозподілити між заходами 3 розквартирування (Свид $=\mathrm{C} 1+\mathrm{C} 2+\mathrm{C} 3)$ таким чином, щоб максимізувати рівень боєздатності $\theta$ з'єднання (частини), що розквартировується. С1 ; С2 ; С3 - фінансові ресурси, що виділяються на відповідний захід.

Отже, на третьому етапі визначаються реальні (виконані) показники розквартирування під виділені фінансові ресурси. Так, для заходу №1 розгортання та обладнання наметового містечка обчислюється реальна кількість $\mathrm{M}_{1}$ наметів або збірно-розбірних житлових конструкцій (од.) за формулою

$$
\mathrm{M}_{1}=\frac{\mathrm{C}_{1}}{\mathrm{c}_{1}}=\frac{\alpha_{1} \cdot \mathrm{N}}{\mathrm{S}} ;
$$

де $\alpha_{1}-$ реальна норма забезпечення військовослужбовців площею.

При цьому цей показник знаходиться в межах від $\alpha{ }_{\text {o1 }}^{\min }$ (мінімальне значення) до $\alpha{ }_{\text {o1 }}^{\max }$ (максимальне значення) відповідно до законодавчо встановлених нормативів i розраховується за формулою

$$
\alpha_{\mathrm{o} 1}{ }^{\text {min }} \leq \alpha_{1}=\mathrm{C}_{1} \cdot \frac{\mathrm{S}}{\mathrm{c}_{1} \cdot \mathrm{N}} \leq \alpha_{\mathrm{o} 1}{ }^{\text {max }} .
$$

Для заходу № 2 розгортання та обладнання пунктів харчового забезпечення обчислення відбуваються аналогічно. Так, реальна кількість $\mathrm{M}_{2}$ наметів або збірно-розбірних житлових конструкцій (од.) за формулою

$$
\mathrm{M}_{2}=\frac{\mathrm{C}_{2}}{\mathrm{c}_{2}}=\frac{\alpha_{2} \cdot \mathrm{N}}{\mathrm{V}} ;
$$

де $\alpha_{2}-$ реальна норма забезпечення військовослужбовців харчуванням.

При цьому цей показник знаходиться в межах від $\alpha \underset{\text { 02 }}{\min }$ (мінімальне значення) до $\alpha{ }_{02}^{\max }$ (максимальне значення) відповідно до законодавчо встановлених нормативів i розраховується за формулою

$$
\alpha_{02}{ }^{\text {min }} \leq \alpha_{2}=\mathrm{C}_{2} \cdot \frac{\mathrm{V}}{\mathrm{c}_{2} \cdot \mathrm{N}} \leq \alpha_{\mathrm{o} 2}{ }^{{ }^{2}}{ }^{2} .
$$

Для заходу № 3 розгортання та обладнання місць для навчань реальна кількість М3 місць для навчань (од.) обчислюється за формулою

$$
\mathrm{M}_{3}=\frac{\mathrm{C}_{3}}{\mathrm{c}_{3}} .
$$

На четвертому етапі оцінюється досяжний рівень $\theta$ боєздатності з'єднання (частини) залежно від показників розквартирування за кожним заходом. Так, для заходу №1 розгортання та обладнання наметового містечка визначається досяжний рівень боєздатності $\theta 1$. Враховуючи (1) та (8), отримаємо таку залежність

$$
\theta_{1}=\frac{M_{1}}{M_{01}}=\frac{\alpha_{1}}{\alpha_{o 1}}=C_{1} \cdot \frac{S}{c_{1} \cdot \alpha_{o 1} \cdot N} .
$$

Аналогічно для заходу № 2 розгортання та обладнання пунктів харчового забезпечення визначається досяжний рівень боєздатності $\theta_{2}$. Враховуючи (3) та (10), отримаємо таку залежність

$$
\theta_{2}=\frac{M_{2}}{M_{02}}=\frac{\alpha_{2}}{\alpha_{02}}=C_{2} \cdot \frac{V}{c_{2} \cdot \alpha_{02} \cdot N} .
$$

Досяжний рівень боєздатності $\theta_{3}$ для заходу № 3 розгортання та обладнання місць для навчань враховуючи (5) та (12) обчислюється за формулою

$$
\theta_{3}=\frac{M_{3}}{M_{03}}=C_{3} \cdot \frac{L}{c_{3} \cdot N} .
$$

На п'ятому етапі вирішується оптимізаційна задача. Розглядуваний процес розквартирування з'єднання (частини) вважається реалізованим, якщо виконані всі зазначені вище незалежні один від одного заходи. Отже, події, пов'язані з цими заходами, є сумісними та незалежними. Виходячи 3 цього, ймовірність впливу результатів проведених заходів з розквартирування 3'єднання (частини) у польових умовах на боєздатність з'єднань (частин) може обчислюватися із використанням теореми добутку ймовірностей для незалежних подій таким чином [5]:

$$
\theta=\theta_{1} \cdot \theta_{2} \cdot \theta_{3} .
$$

Із (16) випливає, що обчислення величини $\theta$ здійснюється на основі визначених згідно (13-15) значень $\theta_{1}, \theta_{2}, \theta_{3}$. Отже,

$$
=\frac{\mathrm{C}_{1} \cdot \mathrm{S}}{\mathrm{c}_{1} \cdot \alpha_{\mathrm{o} 1} \cdot \mathrm{N}} \cdot \frac{\theta_{1} \cdot \theta_{2} \cdot \theta_{3}}{\mathrm{C}_{2} \cdot \alpha_{\mathrm{o} 2} \cdot \mathrm{N}} \cdot \frac{\mathrm{C}_{3} \cdot \alpha_{\mathrm{o} 3}}{\mathrm{c}_{3} \cdot \mathrm{N}} .
$$

Очевидно, що фінансові ресурси $\mathrm{C}_{\text {вид }} \leq \mathrm{C}_{0}$, які виділяються на проведення розглядуваних заходів розквартирування з'єднання (частини) в польових умовах, будуть розподілятися між цими заходами таким чином, щоб виконувалось таке співвідношення: $\mathrm{C}_{1}+\mathrm{C}_{2}+\mathrm{C}_{3}=\mathrm{C}_{\text {вид }}$. Отже, виходячи 3 цього, можна розглядати оптимізаційну задачу, яка передбачає розподіл виділених фінансових ресурсів $\mathrm{C}_{\text {вид }}<\mathrm{C}_{0}$ між заходами розквартирування військ у польових умовах для отримання таких результатів $\mathrm{M}_{1}, \mathrm{M}_{2}, \mathrm{M}_{3}$, які дозволять максимізувати досяжний рівень боєздатності $\theta$, що в даному випадку залежить лише від результатів заходів 3 розквартирування з'єднання (частини):

$\max \theta=\mathrm{C}_{1} \cdot \frac{\mathrm{S}}{\mathrm{c}_{1} \cdot \alpha_{\mathrm{o} 1} \cdot \mathrm{N}} \cdot \mathrm{C}_{2} \cdot \frac{\mathrm{V}}{\mathrm{c}_{2} \cdot \alpha_{\mathrm{O} 2} \cdot \mathrm{N}} \cdot \mathrm{C}_{3} \cdot \frac{\mathrm{L}}{\mathrm{c}_{3} \cdot \mathrm{N}}$, (18)

за обмеженнями $\mathrm{C}_{1}+\mathrm{C}_{2}+\mathrm{C}_{3}=\mathrm{C}_{\text {вид }}$,

де невідомі $\mathrm{C}_{1}, \mathrm{C}_{2}, \mathrm{C}_{3}>0$.

Як бачимо, у даній задачі цільова функція нелінійна, тому в цілому розглядувана оптимізаційна задача належить до задач нелінійного програмування. Вирішення цієї задачі (18) можна здійснювати 
ітераційним способом, що дозволить розв'язати встановлену залежність $\theta=\mathrm{f}\left(\mathrm{C}_{1}, \mathrm{C}_{2}, \mathrm{C}_{3}\right)$.

Завершальним етапом $є$ порівняння досяжного рівня $\theta$ боєздатності з'єднання (частини) та необхідного $\theta{ }^{\text {вим. }}$. При цьому необхідний рівень боєздатності $\theta$ вим встановлює особа, що приймає рішення. Якщо $\theta \geq \theta^{\text {вим }}$, то виділених фінансових ресурсів достатньо для забезпечення необхідного рівня боєздатності з'єднання (частини). В іншому випадку необхідно збільшити виділені ресурси. Очевидно, якщо $\mathrm{C}_{0}$ забезпечує рівень боєздатності з'єднання (частини) на рівні 1 , то для забезпечення необхідного рівня боєздатності $\theta$ вим слід на розквартирування з'єднання (частини) в польових умовах виділити $\mathrm{C}^{\text {вим }}=\mathrm{C}_{0} \cdot \theta^{\text {вим }}$.

Новизною методики, на відміну від існуючого підходу, є:

по-перше, формалізовано взаємозв'язок результатів розквартирування з'єднання (частини) в польових умовах 3 досяжним рівнем його боєздатності;

по-друге, запропоновано механізм розрахунку необхідних фінансових ресурсів для здійснення

\section{Лimepamypa}

1. Проблеми ефективності використання воєнноекономічних ресурсів Збройних Сил України на сучасному етапі. Навч. посібник / За ред. М. М. Кирієнка. Київ: КВГІ, 1998. 180 с. 2. Викулов С.Ф. Экономика военного строительства: эволюция взглядов на проблемы, методы, решения. Москва: успішного розквартирування з'єднання (частини) в польових умовах;

по-третє, здійснено оптимізацію розподілу виділених фінансових ресурсів між заходами розквартирування з'єднання (частини) в польових умовах 3 метою максимізації рівня його боєздатності.

\section{Висновки й перспективи подальших досліджень}

Таким чином, запропонована методика дозволить уникнути помилок під час визначення необхідних фінансових ресурсів для розквартирування з'єднання (частини) в польових умовах, а також здійснювати більш обгрунтований розподіл виділених фінансових ресурсів.

Подальші дослідження будуть пов'язані 3 проведенням чисельного експерименту, що має підтвердити працездатність запропонованої методики, а також розробленням рекомендацій 3 розподілу виділених фінансових ресурсів на розквартирування з'єднань (частин) у польових умовах, що буде сприяти підвищенню боєздатності цих з'єднань (частин).

«Граница», 2013. 608 с. 3. Вентцель Е. С. Теория вероятности и еe инженерные приложения /Е. С. Вентцель, Л. А. Овчаров. Москва: Наука, Главная редакция физико-математической литературы, $1988.478 \mathrm{c}$.

\title{
МЕТОДИКА РАСПРЕДЕЛЕНИЯ ФИНАНСОВЫХ РЕСУРСОВ МЕЖДУ МЕРОПРИЯТИЯМИ РАСКВАРТИРОВАНИЯ СОЕДИНЕНИЙ (ЧАСТЕЙ) В ПОЛЕВЫХ Условиях
}

\author{
Иван Юрьевич Марко (о-р экон. наук, профессор) ${ }^{l}$ \\ Ирина Матвеевна Чернышова (канд. воен. наук, с.н.с.) ${ }^{1}$ \\ Тарас Владимирович Череватый
}

\section{${ }^{1}$ Центральный научно-исследовательский институт Вооруженных Сил Украины, Киев, Украина ${ }^{2}$ Главное квартирно-эксплуатационное управление Вооруженных Сил Украины, Киев, Украина}

В статье представлена улучшенная методика распределения выделенных финансовых ресурсов между мероприятиями, которые выполняются для расквартирования соединений (частей) Вооруженных Сил Украины в полевых условиях с иелью поддержания определенного уровня боеспособности этих соединений (частей). Методика предназначена для обоснования объемов финансовых ресурсов, необходимых для проведения успешного расквартирования соединений (частей) в полевых условиях, а также для определения порядка распределение выделенных финансовых ресурсов между мероприятиями по расквартированию соединений (частей) в полевых условиях. Её применение предлагается в штабах (службах) во время определения потребности в расходных материальных средствах, необходимых для осуществления указанного расквартирования, а также для оптимального распределения выделенных финансовых ресурсов между мероприятиями по расквартированию. Предложенная методика имеет ряд преимуществ: во-первых формализует взаимосвязь результатов расквартирования войск (сил) в полевых условиях с достигаемым уровнем боеспособности; во-вторых содержит механизм расчета необходимых финансовых ресурсов для проведения успешного расквартирования соединений (частей); в-третьих, позволяет оптимизировать распределения выделенных финансовых ресурсов между мероприятиями расквартирования соединения (части) Вооруженных Сил Украины в полевых условиях с иелью максимизировать уровень его боеспособности. Использование улучшенной методики дает возможность избежать ошибок во время определения необходимых финансовых ресурсов для расквартирования войск (сил) в полевых условиях, а также выполнять более обоснованное распределение выделенных финансовых ресурсов. 
Ключевые слова: расквартирование соединений (частей) в полевых условиях; распределение финансовых ресурсов; уровень боеспособности.

\title{
METHODOLOGY OF DISTRIBUTION THE FINANCIAL RESOURCES BETWEEN ACTIVITIES OF HOUSING UNITS (PARTS) IN THE FIELD CONDITIONS
}

\author{
Ivan Marco (Doctor of Economic Sciences, Professor) ${ }^{l}$ \\ Iryna Chenyshova (Candidate of Military Sciences, Senior Research Fellow) ${ }^{1}$ \\ Taras Cherevatyi ${ }^{2}$

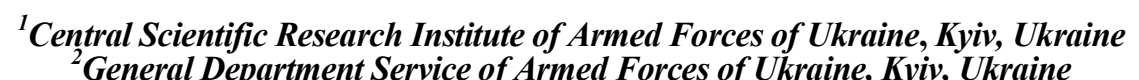

The article presents an improved methodology for allocating the allocated financial resources between the activities that are performed to housing the units (military formations) of the Armed Forces of Ukraine in the field with the purpose of maintaining a certain level of combat capability of these formations (units). The methodology is dedicated to justify the amount of necessary financial resources for the successful housing of unit (military formation) in the field and to determine the allocation of allocated financial resources between the arrangements for housing the units (military formations) of the Armed Forces of Ukraine in the field. Its application is proposed at headquarters (services) during the determination of the need for expendable material resources necessary for the implementation of this quartering, as well as for the optimal allocation of allocated financial resources between the quartering arrangements. The proposed methodology has several advantages: firstly, it formalizes the relationship between the results of housing troops (forces) in the field with the achieved level of combat capability; secondly, it contains a mechanism for calculating the necessary financial resources for the successful housing of units (military formations); thirdly, it allows to optimize the allocation of allocated financial resources between the arrangements for housing the unit (military formation) of the Armed Forces of Ukraine in the field with the aim of maximizing the level of its combat capability. The use of improved methodology makes it possible to avoid mistakes during the determination of the necessary financial resources for housing troops (forces) in the field, and also to carry out a more justified allocation of allocated financial resources.

Key words: housing of units (military formations) in the field; distribution of financial resources; level of combat capability.

\section{References}

1. The problems of effectiveness using military-economic resources of the Armed Forces of Ukraine at the present stage. Teaching manual/ ed. M. M. Kiriyenko. Kyiv: KVGI, 1998. 180 p. 2. Vikulov S.F. Economics of military construction: the evolution of views on problems, methods, solutions. Moscow: "Border", 2013. 608 p. 3. Ventzel E.S. Theory of probability and its engineering applications / E.S. Ventsel, L.A. Ovcharov Moscow: The science, Home Edition of Physical and Mathematical Literature, 1988. $478 \mathrm{p}$. 